\title{
Ulnar Nerve Conduction Study of the First Dorsal Interosseous Muscle in Korean Subjects
}

\author{
Dong Hwee Kim, M.D., Ph.D. \\ Department of Physical Medicine \& Rehabilitation, College of Medicine, Korea University, Ansan 425-707, Korea
}

\begin{abstract}
Objective To derive normative values for ulnar nerve conduction study of the active recording electrode on the first dorsal interosseous muscle (FDI) and the reference electrode on the proximal phalanx of the thumb.

Method Ulnar nerve motor conduction study with FDI and abductor digiti minimi muscle (ADM) recording was performed in 214 hands of 107 healthy subjects. Ulnar NCS was performed with 2 different recording electrode montages (ADM-base of $5^{\text {th }}$ finger; FDI-thumb) and differences in latency and amplitude were compared. Using this technique, the initial positivity of ulnar compound muscle action potential (CMAP) was not observed in any response with FDI recording.

Results The maximal values for distal motor latency to the ADM and FDI muscle were $3.8 \mathrm{~ms}$ and $4.4 \mathrm{~ms}$, respectively. The maximal difference of distal motor latency between the bilateral FDI recordings was $0.6 \mathrm{~ms}$. The maximal ipsilateral latency difference between ADM and FDI was $1.4 \mathrm{~ms}$.

Conclusion Placement of the reference electrode on the thumb results in a CMAP without an initial positivity and the normative values obtained may be useful in the diagnosis of ulnar neuropathy at the wrist.
\end{abstract}

Key Words Nerve conduction, Reference electrode, Thumb, Ulnar neuropathies, Wrist

\section{INTRODUCTION}

Ulnar nerve problems commonly arise in the regions of the elbow and/or wrist. Ulnar neuropathy at the elbow is the second most common entrapment neuropathy in the upper limb. ${ }^{1}$ However, ulnar neuropathy at the wrist

Received January 25, 2011; Accepted July 3, 2011

Corresponding author: Dong Hwee Kim

Department of Physical Medicine \& Rehabilitation, Korea University Ansan Hospital, 516, Gojan-dong, Danwon-gu, Ansan 425-707, Korea Tel: +82-31-412-5330, Fax: +82-31-412-5344, E-mail: rmkdh@korea.ac.kr (ㄷ) This is an open-access article distributed under the terms of the Creative Commons Attribution Non-Commercial License (http:// creativecommons.org/licenses/by-nc/3.0) which permits unrestricted noncommercial use, distribution, and reproduction in any medium, provided the original work is properly cited.

Copyright $\odot 2011$ by Korean Academy of Rehabilitation Medicine
(UNW) is a rare disease entity and is sometimes confused with ulnar neuropathy at the elbow. ${ }^{2}$ Various techniques have been developed to diagnose UNW. ${ }^{2-10}$ Among these, ulnar nerve conduction study on the first dorsal interosseous muscle (FDI) is very useful. ${ }^{3}$ Preston and Shapiro suggested that ulnar motor nerve conduction study with FDI recording should be done in all patients with suspected UNW. However, the short-coming of FDI recording is the initial positive deflection of compound muscle action potential (CMAP), which poses a problem in measuring distal motor onset latency.

In 1990, Wertsch et al. demonstrated that the initial positive deflection was strongly influenced by the position of the reference recording electrode, and the reference 


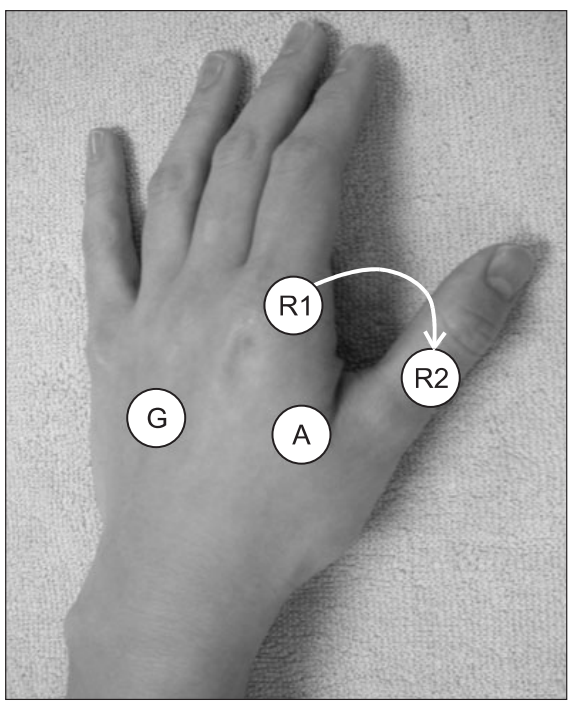

Fig. 1. The position of the reference electrode in the ulnar motor nerve conduction study with the first dorsal interosseous recording: R1: Olney \& Wilbourn's method ${ }^{3}$, R2: The author's method. A: active electrode, G: ground electrode.

electrode placement on the thumb could avoid an initial positive deflection that may be seen when the reference is placed on the index finger (Fig. 1, 2). ${ }^{11}$ Phongsamart et al. also demonstrated that the CMAP waveform shape and onset latency could be affected by the different reference electrode position. ${ }^{12}$ Recent researchers also used the base of the thumb as a reference electrode for FDI recording. ${ }^{10,12-14}$

This study was designed to derive normative values of ulnar nerve conduction study with the recording electrode on the FDI muscle and the reference electrode on the proximal phalanx of thumb.

\section{METERIALS AND METHODS}

Nerve conduction study (NCS) was performed in 214 hands of 107 healthy subjects consisting of 54 women and 53 men (mean age, $42.6 \pm 11.2$ years). None of the subjects had symptoms and signs of systemic or neurologic disease. Subjects that fulfilled any American Association of Neuromuscular \& Electrodiagnostic Medicine criteria for ulnar neuropathy on the elbow were also excluded. This study was approved by the local ethical committee and was performed with consent from each healthy subject and patient.

Ulnar motor nerve conduction study was performed

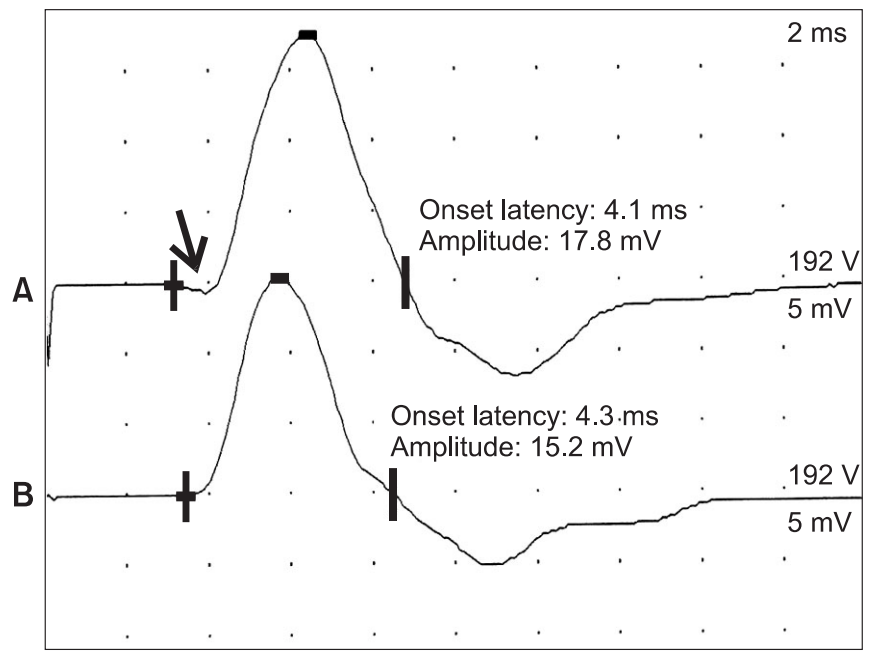

Fig. 2. Ulnar compound muscle action potentials with first the dorsal interosseous recording and the same stimulation intensity according to each reference electrode position in a healthy person: (A) Olney \& Wilbourn's method ${ }^{3}$ shows an initial positive deflection (arrow); (B) no initial positive deflection was recorded in any responses obtained by the author's method.

separately with both abductor digiti minimi (ADM) and FDI muscles in healthy subjects and patients with UNW. The active recording electrodes were placed over the belly of each muscle and the reference electrodes were applied on the base of the proximal phalanx bone of the fifth digit for the ADM and the proximal phalanx of the thumb for the FDI. The ulnar nerve was stimulated at the wrist (8 $\mathrm{cm}$ proximal to the active recording electrode for ADM), $3 \mathrm{~cm}$ distal to the medial epicondyle, and $7 \mathrm{~cm}$ proximal to medial epicondyle with the elbow placed in 90 degrees flexion. Stimulation was applied with sufficient intensity to evoke a supramaximal response at each stimulation site. Surface recording and stimulation electrodes were used for this study. Distal onset latency and baseline-topeak amplitude of the ulnar CMAP to ADM and FDI were measured. Ipsilateral distal latency difference between FDI and ADM was calculated. Side-to-side differences in latency and amplitude to each muscle were also calculated.

All nerve conduction studies were performed with a Nicolet Viking IV Electrodiagnostic System (Nicolet Instrument Corp., Madison, USA). For the ulnar motor nerve conduction study of the FDI muscle, the filter was set at a low-frequency filter of $2 \mathrm{~Hz}$ and high-frequency filter of $10 \mathrm{kHz}$, and sensitivity and sweep speed were set 
at $5 \mathrm{mV} /$ division and $1 \mathrm{~ms} /$ division, respectively. The skin temperature was maintained above $32^{\circ} \mathrm{C}$ with a thermal sensor placed on the surface of the FDI.

\section{Statistical analysis}

We considered the maximal value for the latency and latency difference as the upper normal limit, and the minimal value for amplitude as the lower normal limit. The values of distal motor latency to FDI and $\mathrm{ADM}$, ipsilateral latency differences between ADM and

Table 1. Demographic Data of Healthy Subjects in this Study

\begin{tabular}{lrcc}
\hline & Mean & SD & Range \\
\hline Age (years) & 42.6 & 11.2 & $23-71$ \\
Men & 40.0 & 11.4 & $23-71$ \\
Women & 45.2 & 10.4 & $25-71$ \\
Weight $(\mathrm{kg})$ & 63.9 & 12.0 & $41-90$ \\
Men & 71.8 & 9.7 & $53-90$ \\
Women & 56.1 & 8.3 & $41-84$ \\
\hline Height $(\mathrm{cm})$ & 164.9 & 8.9 & $145-185$ \\
Men & 171.7 & 6.0 & $155-185$ \\
Women & 158.2 & 5.7 & $145-178$ \\
BMI $\left(\mathrm{kg} / \mathrm{m}^{2}\right)$ & 23.4 & 3.3 & $17.4-33.1$ \\
Men & 24.4 & 3.1 & $18.9-33.1$ \\
\hline Women & 22.4 & 3.2 & $17.4-28.9$ \\
\hline
\end{tabular}

BMI: Body mass index, SD: Standard deviation

Table 2. Normative Values for Electrophysiologic Study for Ulnar Neuropathy at the Wrist

\begin{tabular}{|c|c|c|c|}
\hline \multirow{2}{*}{ Parameters } & \multicolumn{3}{|c|}{$\mathrm{n}=214$ hands } \\
\hline & Maximal & 95\%ile & Mean+2SD \\
\hline DML to ADM (ms) & 3.8 & 3.4 & 3.5 \\
\hline DML to FDI (ms) & 4.4 & 4.1 & 4.2 \\
\hline $\begin{array}{l}\text { Ipsilateral LD between } \\
\text { FDI and ADM (ms) }\end{array}$ & 1.4 & 1.1 & 1.1 \\
\hline $\begin{array}{l}\text { Side-to-side LD } \\
\text { to ADM (ms) }\end{array}$ & 0.5 & 0.3 & 0.4 \\
\hline $\begin{array}{l}\text { Side-to-side LD } \\
\text { to FDI (ms) }\end{array}$ & 0.6 & 0.4 & 0.4 \\
\hline Parameters & Minimal & 5\%ile & Mean-2SD \\
\hline Amplitude of ADM (mV) & 7.0 & 8.7 & 7.6 \\
\hline Amplitude of FDI (mV) & 8.4 & 9.4 & 7.4 \\
\hline
\end{tabular}

DML: Distal motor latency, ADM: Abductor digiti minimus, FDI: First dorsal interosseous, SD: Standard deviation, LD: Latency difference
FDI, side-to-side latency difference of ADM and FDI responses, and CMAP amplitudes recorded over ADM and FDI were presented as mean, standard deviation, median, minimal and maximal, and $5^{\text {th }}$ or $95^{\text {th }}$ percentile value. Paired t-test was used to test for side-to-side differences and independent t-test for gender differences. To build the models between the electrophysiogic parameters and independent variables, such as age, height, weight and BMI, multiple regression analysis was performed in the forward stepwise method. A p-value of less than 0.05 was considered statistically significant. The statistical package SPSS version 12.0 was used for the analysis of all data.

\section{RESULTS}

The demographic data of all healthy subjects are presented (Table 1). Normative values for the electrophysiologic study for UNW as the maximal value, 95 percentile value, and mean+2SD of latency of ADM and

Table 3. Mean and Range for Distal Motor Latency by Decade (214 Hands)

\begin{tabular}{lccccc}
\hline \multirow{2}{*}{$\begin{array}{c}\text { Age } \\
\text { (years) }\end{array}$} & \multirow{2}{*}{$\mathbf{N}$} & \multicolumn{2}{c}{ ADM (ms) } & \multicolumn{2}{c}{ FDI (ms) } \\
\cline { 3 - 6 } & & Mean & Range & Mean & Range \\
\hline $20-29$ & 30 & 2.8 & $2.4-3.4$ & 3.4 & $3.1-4.2$ \\
$30-39$ & 66 & 2.8 & $2.3-3.5$ & 3.5 & $3.0-4.0$ \\
$40-49$ & 58 & 2.9 & $2.4-3.6$ & 3.7 & $2.9-4.4$ \\
$50-59$ & 40 & 2.9 & $2.5-3.8$ & 3.7 & $3.2-4.2$ \\
$60-$ & 20 & 3.1 & $2.7-3.8$ & 3.7 & $3.3-4.1$ \\
Total & 214 & 2.9 & $2.3-3.8$ & 3.6 & $2.9-4.4$ \\
\hline
\end{tabular}

ADM: Abductor digiti minimus, FDI: First dorsal interosseous, N: Number of hands

Table 4. Mean and Range for Amplitude by Decade (214 Hands)

\begin{tabular}{cccccc}
\hline \multirow{2}{*}{$\begin{array}{c}\text { Age } \\
\text { (years) }\end{array}$} & N & \multicolumn{2}{c}{ ADM $(\mathbf{m V})$} & \multicolumn{2}{c}{ FDI $(\mathbf{m V})$} \\
\cline { 3 - 6 } & & Mean & Range & Mean & Range \\
\hline $20-29$ & 30 & 12.9 & $8.8-16.4$ & 14.9 & $10.6-22.3$ \\
$30-39$ & 66 & 12.4 & $8.3-18.1$ & 14.2 & $8.7-22.4$ \\
$40-49$ & 58 & 11.9 & $7.0-15.4$ & 14.6 & $10.0-23.5$ \\
$50-59$ & 40 & 11.6 & $7.5-17.5$ & 12.9 & $8.4-20.9$ \\
$60-$ & 20 & 10.6 & $8.8-13.6$ & 12.5 & $10.2-16.8$ \\
\hline Total & 214 & 11.9 & $7.0-18.1$ & 14.1 & $8.4-23.5$ \\
\hline
\end{tabular}

ADM: Abductor digiti minimus, FDI: First dorsal interosseous, $\mathrm{N}$ : Number of hands 
FDI, and the minimal value, 5 percentile value, and mean-2SD of amplitude of ADM and FDI are presented (Table 2). The mean and range for distal motor latency to ADM and FDI by decade are presented in Table 3 and the mean and range for baseline-to-negative peak amplitudes of ADM and FDI according to each decade of age are presented in Table 4. There was a tendency for the CMAP amplitudes of both muscles to decrease with advancing age, but no association was observed between minimal value and age. There was no significant rightleft difference in CMAP amplitudes of ADM, but there was a significant right-left amplitude difference for FDI recordings, in which mean CMAP amplitude was $14.6 \mathrm{mV}$ in the right and $13.6 \mathrm{mV}$ in the left $(\mathrm{p}<0.05)$.

According to the forward stepwise multiple regression analysis performed on the distal motor latency to ADM (DML_ADM) and FDI (DML_FDI), the models for multiple linear regression were $\mathrm{y}_{\mathrm{DML} \_\mathrm{ADM}}=$ $1.455+0.11 \times$ age $+0.006 \times$ height $\left(\mathrm{p}=0.000 ; \mathrm{R}^{2}=0.184\right)$ and $\mathrm{y}_{\mathrm{DML}_{-} \mathrm{FDI}}=01.426+0.013 \times$ age $+0.01 \times$ height $(\mathrm{p}=0.000$; $\mathrm{R}^{2}=0.180$ ), respectively. For CMAP amplitude of ADM (AMP_ADM) and FDI (AMP_FDI), the models for multiple linear regression were $\mathrm{y}_{\mathrm{AMP}_{-} \mathrm{ADM}}=14.657-0.064$ age $(\mathrm{p}=$ $\left.0.000 ; \mathrm{R}^{2}=0.105\right)$ and $\mathrm{y}_{\mathrm{AMP} \_ \text {FDI }}=17.296-0.075 \times$ age $(\mathrm{p}=0.000$; $\mathrm{R}^{2}=0.067$ ), respectively. For side-to-side latency difference to ADM (SIDE_ADM) and FDI (SIDE_FDI), the equations for multiple linear regression were $\mathrm{y}_{\text {SIDE_ADM }_{A}}=0.182$ $0.004 \times$ age $\left(\mathrm{p}=0.018 ; \mathrm{R}^{2}=0.061\right)$ and $\mathrm{y}_{\text {SIDE_FDI }_{1}}=0.260$ $0.006 \times$ age $\left(p=0.03 ; R^{2}=0.094\right)$, respectively. For ipsilateral latency difference between FDI and ADM, there was no significant variable among age, height, weight, and BMI. There was no initial small positive deflection in any ulnar nerve conduction study with FDI recording.

\section{DISCUSSION}

UNW has diverse clinical findings including pure sensory, pure motor, and combined motor and sensory symptoms according to the location of lesion in the wrist. Electrophysiologic evaluation for suspected UNW has to include nerve conduction studies to evaluate motor fibers to ADM and FDI and sensory fibers to $5^{\text {th }}$ digit. Preston and Shapiro ${ }^{15}$ recommended a routine nerve conduction study protocol for ulnar neuropathy at the wrist as follows: 1) ulnar motor study recording ADM; 2) ulnar motor study recording FDI (bilateral studies);
3) short segment increment study of ulnar motor nerve across the wrist recording FDI; 4) Median motor study recording $\mathrm{APB}$; 5) median and ulnar F responses; 6) ulnar sensory response recording digit 5 (bilateral studies); 7) median sensory response recording digit 2 or 3 ; 8) dorsal ulnar cutaneous sensory response (bilateral studies); and 9) lumbrical-interosseous distal latency comparison study. Among these, it is essential to perform the ulnar motor conduction study recording the FDI in patients with lesions of deep palmar motor branches. Distal latency to FDI, side-to-side latency difference to FDI, and ipsilateral latency difference between FDI and ADM are often helpful in the diagnosis of UNW and their normal criteria are $4.5 \mathrm{msec}, 2.0$ msec, and $1.3 \mathrm{msec}$, respectively, reported by Olney and Wilbourn. ${ }^{3}$ These criteria have been recited in many electrodiagnostic texts. However, their method using the $2^{\text {nd }}$ metacarpophalangeal joint as a reference electrode brought about a problem in measuring the distal motor latency to FDI, which was an initial positive deflection. This initial positive deflection is influenced not by the position of active recording electrode on FDI but by the position of the reference recording electrode, and the change of reference electrode placement to the thumb from the index finger can avoid this initial deflection. As the ulnar nerve conduction study is performed in the FDI, the thumb over the index finger is preferred by many as a reference electrode position because the initial positive deflection can be avoided. ${ }^{10,12-14}$ This situation required the development of new normal criteria for the diagnosis of UNW using the modified ulnar motor nerve conduction study with FDI recording. We performed ulnar motor nerve conduction study to the FDI with the reference electrode placed on the thumb in 214 hands of 107 healthy persons and obtained the maximal values as the normal criteria to compare with Olney and Wilbourn's study. ${ }^{3}$ There was no significant difference in the distal latency to FDI and ADM. However, our study revealed that the ipsilateral latency difference between FDI and ADM, side-to-side latency difference to ADM, and side-to-side latency difference to FDI were shorter than those of Olney and Wilbourn's study (Table 2). ${ }^{3}$ We postulate that the shorter side-to-side latency to ADM or FDI in our study may be caused by the differences of stimulation site and the different position of reference recording electrode. Olney and Wilbourn's study used 
the proximal wrist crease as stimulation site, which may cause differences in stimulation distance between both sides. ${ }^{3}$ In this study, the ulnar nerve was stimulated a point $8 \mathrm{~cm}$ proximal to the active recording electrode site on the ADM for both ADM and FDI recordings which allowed a more uniform stimulation distance compared to Olney and Wilbourn's findings. ${ }^{3}$ Also, the change of reference electrode placement to the thumb from the index finger would be helpful to eliminate the measurement error by the initial positive deflection. The maximal values considered as the normal upper limit of distal latency to FDI, side-to-side latency difference to FDI, and ipsilateral latency difference between FDI and ADM were $4.4 \mathrm{~ms}, 0.6 \mathrm{~ms}$, and $1.4 \mathrm{~ms}$, respectively. The CMAP amplitudes of ADM and FDI recordings in this study were all greater than those of the previous study, and in contrast to the previous study, our study revealed smaller minimal amplitude of ADM than the FDI: ADM, 7.0 mA; FDI, 8.4 mA.

We analyzed our electrophysiologic and demographic data with the forward stepwise multiple regression method and formulated regression equations. Although all equations were statistically significant $(\mathrm{p}<0.000)$, the small coefficients of determination $\left(\mathrm{R}^{2}, 0.061-0.184\right)$ of each formula and the small regression coefficients (0.004-0.11) indicated that this model was inadequate for explaining the variation of many dependent variables useful for diagnosing UNW. In particular, equations for distal latency to and amplitude of FDI, side-to-side latency difference to ADM and FDI showed a very small coefficient of determination and regression coefficients. Also, there was no statistically significant correlation in the ipsilateral latency difference between FDI and ADM with age, height, weight, and BMI. The results of regression analysis suggest that these parameters may be useful in the diagnosis of UNW regardless of age, sex, height, weight, and BMI.

\section{CONCLUSION}

In conclusion, considering the current trend of the thumb being used as a reference in the ulnar nerve conduction study to FDI, the results of our study may be very meaningful in the diagnosis of UNW. Although the maximal values are used as normal upper criteria for latency to compare with the previous study, the $95^{\text {th }}$ percentile or 'mean+SD' values may be applied as normal criteria. However, as these values can increase sensitivity and decrease specificity of UNW, they should be used with caution. Because the incidence of UNW is rare, using the maximal values may be a safer method that can decrease false positives.

Further studies need to be performed in patients suspected with UNW to prove the usefulness of ulnar nerve conduction studies of the recording electrode on the FDI muscle and the reference electrode on the proximal phalanx of the thumb.

\section{REFERENCES}

1. Tackmann W, Vogel P, Kaeser HE, Ettlin T. Sensitivity and localizing significance of motor and sensory electroneurographic parameters in the diagnosis of ulnar nerve lesions at the elbow. A reappraisal. J Neurol 1984; 231: 204-211

2. Olney RK, Hanson M. AAEE case report \#15: ulnar neuropathy at or distal to the wrist. Muscle Nerve 1988;11: 828-832

3. Olney RK, Wilbourn AJ. Ulnar nerve conduction study of the first dorsal interosseous muscle. Arch Phys Med Rehabil 1985; 66: 16-18

4. Ebeling P, Gilliatt RW, Thomas PK. A clinical and electrical study of ulnar nerve lesions in the hand. J Neurol Neurosurg Psychiatry 1960; 23: 1-9

5. Carpendale MT. The localization of ulnar nerve compression in the hand and arm: an improved method of electroneuromyography. Arch Phys Med Rehabil 1966; 47: 325-330

6. Jabre JF. Ulnar nerve lesions at the wrist: new technique for recording from the sensory dorsal branch of the ulnar nerve. Neurology 1980; 30: 873-876

7. Streib EW, Sun SF. Distal ulnar neuropathy in meat packers. An occupational disease?. J Occup Med 1984; 26: 842-843

8. Kothari MJ. Ulnar neuropathy at the wrist. Neurol Clin 1999; 17: 463-476

9. McIntosh KA, Preston DC, Logigian EL. Shortsegment incremental studies to localize ulnar nerve entrapment at the wrist. Neurology 1998; 50: 303-306

10. Cowdery SR, Preston DC, Herrmann DN, Logigian EL. Electrodiagnosis of ulnar neuropathy at the wrist: conduction block versus traditional tests. Neurology 
2002; 59: 420-427

11. Wertsch JJ, Park TA, Lomas JN, Melvin JL. Effect of reference electrode position on deep ulnar nerve conduction studies. Muscle Nerve 1990; 13: 862

12. Phongsamart G, Wertsch JJ, Ferdjallah M, King JC, Foster DT. Effect of reference electrode position on the compound muscle action potential (CMAP) onset latency. Muscle Nerve 2002; 25: 816-821

13. Kothari MJ, Heistand M, Rutkove SB. Three ulnar nerve conduction studies in patients with ulnar neuropathy at the elbow. Arch Phys Med Rehabil 1998
;79: 87-89

14. Park YK, Kwon HK, Lee HJ, Yoon DW, Ha KW. Abductor digiti minimi and first dorsal interosseous recordings for the localization of ulnar neuropathy at the elbow. J Korean Acad Rehab Med 2005; 29: 598601

15. Preston DC, Shapiro BE. Electromyography and neuromuscular disorders: clinical-electrophysiologic correlations, 2nd ed, Philadelphia, Elsevier, 2005, 313326 